\title{
Gallstone ileus in geriatric patients: a report of two cases
}

\author{
Ismail Burud ${ }^{1}$, MBBS, MS, Ravindranath Shroff ${ }^{1}$, MS FRCS, Mahadevan Tata ${ }^{2}$,
} MBBS, MS

\begin{abstract}
Gallstone ileus is a mechanical obstruction of the small intestine caused by gallstone impaction. It accounts for $1 \%$ to $4 \%$ of all cases of mechanical obstruction. Previous acute cholecystitis results in development of a fistula between the gallbladder and the gastrointestinal tract. Diagnosing gallstone ileus is difficult as symptoms and signs are non-specific and most patients are elderly with multiple comorbidities. We report two cases of gallstone ileus in elderly patients. The first case is a 72-yearold man with multiple comorbidities who presented with vomiting, intermittent colicky right-sided abdominal pain, and inability to pass motion. He underwent enterolithotomy alone. The second case is a 73-year-old woman who presented with abdominal pain, distension, fever, and a fistulous communication between the gallbladder and the duodenum. She underwent enterolithotomy, partial cholecystectomy, and closure of the fistula.
\end{abstract}

Key words: Gallstone; Ileus

\section{CASE REPORT}

\footnotetext{
Department of Surgery, International Medical University, Seremban, Malaysia

2 Hospital Tuanku Jaafar, Jalan Rasah, Seremban, Negri Sembilan, Malaysia
}

Correspondence to: Ismail Burud, Senior Lecturer, Department of Surgery, International Medical University, Seremban, 70300, Malaysia.

Email:mohammedburud@hotmail.com

\section{INTRODUCTION}

Gallstone ileus is a rare complication of cholelithiasis and accounts for $25 \%$ of non-strangulated small intestinal obstruction. ${ }^{1}$ It is a surgical emergency in elderly patients who usually present with non-specific symptoms such as abdominal pain, distension, nausea, and vomiting., ${ }^{2,3}$ Bilio-enteric fistula is caused by recurrent inflammation secondary to cholelithiasis, with cholecystoduodenal fistula more common than cholecystocolonic fistula (89\% vs $11 \%) .{ }^{3,4}$ Most patients are older women with multiple comorbidities, and the mortality is high (10\% to $18 \%) .{ }^{1,5}$ Radiography, ultrasonography, and computed tomography of the abdomen are important tools for diagnosis. Surgical options remain controversial in terms of whether to perform a single-stage or two-stage procedure for enterlithotomy, stone removal with cholecystectomy, and repair of fistula. Enterlithotomy alone is a suitable option for patients who are unstable and have multiple comorbidities.

\section{CASE REPORTS}

\section{Patient 1}

In June 2015, a 72-year-old man with hypertension, beta thalassaemia, and end-stage renal failure presented with vomiting ( $>10$ times a day for 3 days), intermittent colicky right-sided abdominal pain, and inability to pass motion. On examination, he was mildly dehydrated with a soft non-distended abdomen and no palpable mass. His electrolyte levels were deranged and creatinine level was elevated and required dialysis. Radiography of the abdomen showed a dilated small bowel. Computed tomography of the abdomen revealed the presence of pneumobilia within the common bile duct and intrahepatic duct, and a fistula between the gallbladder and a large calculus within the small bowel at the jejunoileal junction (FIGURE $\mathbf{1}$ ). Emergency laparotomy and enterolithotomy were performed, and a stone $(2 \times 2 \mathrm{~cm})$ was removed 20 $\mathrm{cm}$ from the ileocecal junction. Postoperatively, the patient recovered well. 


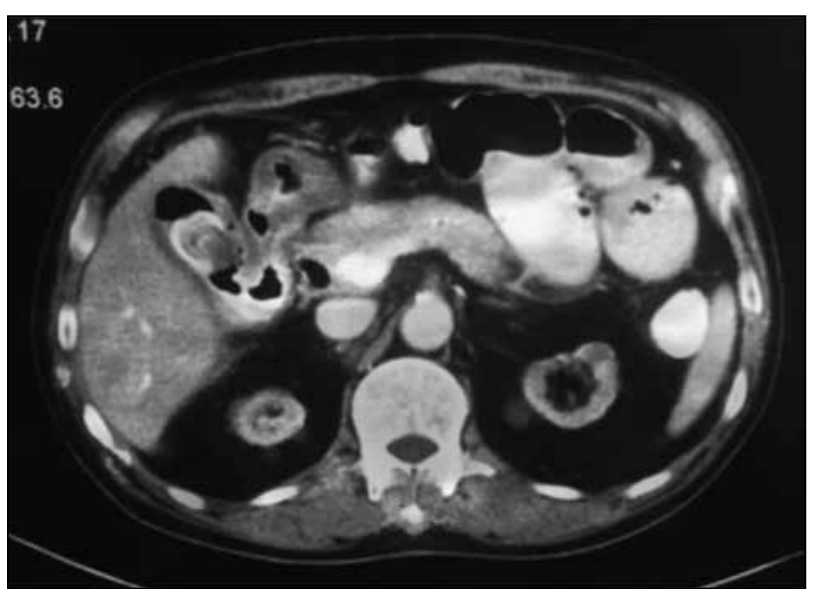

Figure 1. Patient 1: a computed tomographic scan showing pneumobilia.

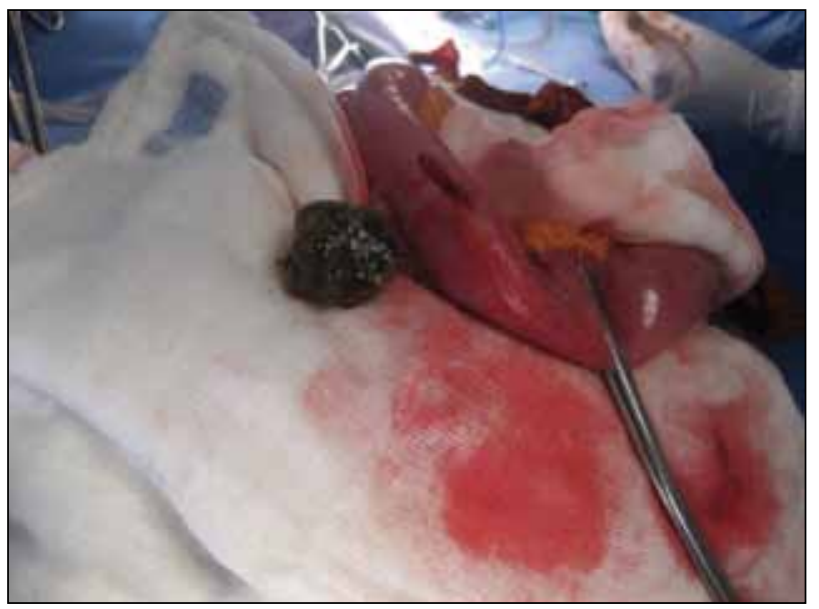

Figure 2. Patient 2: enterolithotomy and the gallstone.

\section{Patient 2}

In December 2014, a 73-year-old woman with hypertension presented with a 1-month history of abdominal pain. She reported vomiting, abdominal distension, and low-grade fever 2 days prior to admission. On examination, her abdomen was distended and tender at the right hypochondrium. Ultrasonography of the abdomen revealed multiple gallstones and mild thickening of the gallbladder wall. Computed tomography showed pnuemobilia and gallstones at the proximal ileum. Intraoperatively, adhesions were noted between the gallbladder and the duodenum in the region of the fistula. Enterlithotomy, partial cholecystectomy, and closure of the fistula were performed (FIGURE 2). Postoperatively, the patient recovered well and was discharged on day 4 .

\section{DISCUSSION}

Cholelithiasis affects $10 \%$ to $20 \%$ of adults in a western population, ${ }^{3}$ and is easily diagnosed by ultrasonography of the abdomen. It may cause gallstone ileus and result in severe morbidity and mortality. Gallstone ileus is often seen in geriatric patients with multiple comorbidities. Biliary symptoms preceding the presentation is rare, and only $50 \%$ of patients with gallstone ileus have a history of biliary disease. ${ }^{6}$ In a case series, abdominal pain and vomiting were common symptoms in all patients except one. ${ }^{7}$

Gallstone ileus has a mortality as high as $18 \%$ and a morbidity of $37.5 \%{ }^{1,3}$ Radiography, ultrasonography, and computed tomography are important tools for diagnosis; featuresinclude dilated bowelloops, calcific shadow in the bowel loops, presence of gallstones, and pneumoblia. ${ }^{5}$ Treatment options include a onestage procedure that involves enterolithotomy (to remove the obstruction), cholecystectomy, and repair of the fistula; or a two-stage procedure that involves enterolithotomy (to remove the obstruction), followed by cholecystectomy and repair of the fistula at a later date. ${ }^{1,3,4,7}$ The optimal choice depends on the patient's general condition and American Society of Anesthesiologists (ASA) score. Enterolithotomy alone is suitable for patients with an ASA score of 4 who are haemodynamically unstable. The risk of developing acute cholecystitis, recurrent gallstone ileus or cholangitis following enterolithotomy alone is $5 \%$ to $17 \% .{ }^{1,7}$ Management with lithotripsy has been performed in a small number of patients. ${ }^{8} \mathrm{~A}$ delay in diagnosis increases morbidity and mortality; timely intervention is important in the care of elderly patients.

\section{ACKNOWLEDGEMENTS}

We would like to thank the Director General of Health Malaysia for his permission to publish this article (registered reference No. NMRR-17-15333962).

\section{DECLARATION}

The authors have no conflicts of interest to disclose.

\section{REFERENCES}

1. Reisner RM, Cohen JR. Gallstone ileus: a review of 1001 reported 
cases. Am Surg 1994;60:441-6.

2. Zuber-Jerger I, Kullmann F, Schneidewind A, Scholmerich J. Diagnosis and treatment of a patient with gallstone ileus. Nat Clin Pract Gastroenterol Hepatol 2005;2:331-5. Crossref

3. Pavlidis TE, Atmatzidis KS, Papaziagos BT, Papaziogas TB. Management of gallstone ileus. J Hepatobiliary Pancreat Surg 2003;10:299-302. Crossref

4. Conzo G1, Mauriello C, Gambardella C, et al. Gallstone ileus: one-stage surgery in an elderly patient: one-stage surgery in gallstone ileus. Int J Surg Case Rep 2013;4:316-8. Crossref
5. Riaz N, Khan MR, Tayeb M. Gallstone ileus: retrospective review of a single centre's experience using two surgical procedures. Singapore Med J 2008;49:624-6.

6. Ravikumar R, Williams JG. The operative management of gallstone ileus. Ann R Coll Surg Engl 2010;92;279-81. Crossref

7. Clavien PA, Richon J, Burgan S, Rohner A. Gallstone ileus. Br J Surg 1990;77:737-42. Crossref

8. Nuno-Guzman CM, Marin-Contreras ME, Figueroa-Sanchez M, Corona JL. Gallstone ileus, clinical presentation, diagnostic and treatment approach. World J Gastrointest Surg 2016;8:65-76. Crossref 